\title{
AGRICULTURA ORGÂNICA: RELATO DE UMA EXPERIÊNCIA
}

Este texto não é propriamente uma produção, utilizando um método sistematizado, de reflexões do universo da Sociologia. Este autor foi convidado a participar desse debate sobre agroecologia em função da experiência como agrônomo e produtor rural de hortaliças orgânicas, fazendo um relato ou descrição dessas experiências. Por esse motivo, justifica-se a utilização do sujeito na primeira pessoa em grande parte do texto. Portanto, as considerações apresentadas analisam a vida prática e os desafios dessa iniciativa e apenas indiretamente se relacionam com o tema proposto inicialmente.

Como bem escreveu Zander Navarro (2013) no seu artigo, esse debate está carregado de injunções morais e emocionais movidas por dogmas que não permitem a crítica construtiva. Por isso, inicio meu comentário com minha trajetória pessoal para que não restem dúvidas sobre as minhas opções e a vontade de participar dessa discussão em alto nível. Posteriormente, comento sobre a experiência em agricultura ecológica que coordenei - a empresa "Horta \& Arte". Concluo com breves considerações que avaliam a iniciativa e seus desafios.

\section{BREVES ANTECEDENTES PESSOAIS}

Nasci em uma família metodista e, desde jovem, fui induzido a pensar sobre o meu trabalho e sobre minha profissão sob uma perspectiva de "missão". Minha formação religiosa também foi fortemente influenciada pela Teologia da Libertação, e, ainda adolescente, tornei-me socialista e militante do Partido dos Trabalhadores. Apesar de nunca ter vivido em regiões rurais, a questão da reforma agrária me interessou e resolvi cursar a faculdade de Agronomia na Universidade Federal Rural do Rio de Janeiro para servir a essa causa. Na Universidade, tive a oportunidade de participar ativamente do movimento estudantil, que questionava o modelo curricular ligado à "agricultura moderna" e, assim, abracei a causa da "agricultura alternativa". Participei ativamente de quase todos os EBAAs (os encontros nacionais que discutiam a agricultura alternativa) e militei no grupo de agricultura alternativa da Faculdade, no Centro Acadêmico, na Co-

\footnotetext{
${ }^{1}$ Engenheiro Agrônomo e proprietário da empresa Horta \& Arte (São Roque/SP). info@hortaearte.com.br 
missão Pastoral da Terra (CPT) e no Partido dos Trabalhadores.

Em 1989, fui convidado por Dom Mauro Morelli, conhecido bispo progressista da Igreja Católica, para participar da formação de um Centro de Agricultura Alternativo na Baixada Fluminense. Foi pioneira experiência que demonstrou os enormes desafios práticos de construir concretamente uma agricultura alternativa. Convidado por uma ONG italiana, que atuava em um assentamento de reforma agrária na Baixada Fluminense, passei a atuar na equipe técnica da cooperativa de agricultores de um assentamento de reforma agrária na Baixada. Trabalhei, então, com dois agrônomos hoje expoentes da agroecologia: Paulo Petersen e Luciano Silveira. Encontramos, no entanto, poucos agricultores aptos a desenvolver uma agricultura ecológica. Muito pobres, eram produtores que não podiam assumir os riscos econômicos correspondentes a esse padrão de agricultura.

Foram experiências frustrantes, pois o sonho da agricultura alternativa se transformara em meu projeto de vida. Eu já apoiava voluntariamente a Associação de Agricultores Biológicos do Estado do Rio de Janeiro ( $\mathrm{ABIO}$ ), mantendo contato com agricultores que produziam alimentos segundo as normas da Agricultura Biológica.

\section{A EXPERIÊNCIA DA EMPRESA “HORTA \& ARTE”}

Em 1992, herdei um sítio de 24 ha na cidade de São Roque, no chamado "cinturão verde" da Grande São Paulo (distante $60 \mathrm{~km}$ da capital). Apesar de minha origem urbana e da preferência por atuar em iniciativas relacionadas à reforma agrária, decidi tornar-me agricultor para desenvolver livremente o sonho de produzir alimentos dentro de uma perspectiva ecológica e saudável. Na época, a produção de alimentos orgânicos estava restrita a poucas experiências no Rio de Janeiro, São Paulo, Curitiba e Porto Alegre. Essas experiências eram, em sua grande maioria, de horticultores com o perfil semelhante ao meu: jovens idealistas com diplomas universitários que abraçaram a causa da produção de alimentos saudáveis. Esses horticultores comercializavam sua produção agrícola em feiras de produtores organizadas por associações de produtores orgânicos, biológicos ou ecológicos. Associei-me à Associação de Agricultura Orgânica (AAO) e resolvi transformar a minha propriedade agrícola em um estabelecimento diversificado e voltado para atender aos consumidores de produtos orgânicos da feira da Associação.

Tive problemas de consciência política, pois era um jovem socialista que se tornara um capitalista. Além disso, o drama se aprofundou quando precisei demitir um funcionário. Ironias à parte, o meu primeiro grande desafio foi criado por mim mesmo. Recebi uma lucrativa propriedade especializada na produção de leite, mas resolvi diversificar a produção para seguir os cânones da agricultura orgânica, que preconiza a diversificação e a integração da produção animal e vegetal dentro de uma propriedade orgânica. Dessa forma, iniciei o plantio de mais de trinta tipos de hortaliças, aproveitando o esterco do gado como adubo, além da produção de mel para aproveitar o potencial apícola da mata nativa, da criação de galinhas poedeiras caipiras e de porcos para aproveitar os restos da produção de hortaliças. Adicionalmente, resolvi produzir iogurte para agregar valor ao leite. A propriedade ficou linda e ecológica, mas precisei justificar ao meu pai, porque eu precisava de seu "pai-trocínio" para cobrir o prejuízo do empreendimento. Foi a 
primeira lição: percebi que a diversificação requer um limite, pois seu excesso promove um aumento na complexidade administrativa, além de não permitir um ganho de escala mínima para se conseguir produtividade e qualidade que atendam aos padrões exigidos pelo mercado.

Após esse fiasco econômico inicial, decidi especializar a produção e focar somente na produção de leite e hortaliças. Alguns anos mais tarde, conduzi para redução ainda maior - deixei de ter gado e foquei apenas na produção de hortaliças.

Outra lição importante foi perceber, ao contrário do senso comum do movimento orgânico da época, que os consumidores que frequentavam a feira da AAO faziam suas escolhas em função do preço e, principalmente, da beleza dos produtos in natura. A ampla diversificação da produção de hortaliças em uma única propriedade para atender a critérios ecológicos consagrados não nos garantia obter um produto bonito e barato. $E$, surpreendentemente, essa diversificação também não permitia um manejo ecológico da produção. As necessidades de irrigação e nutrição são diferentes entre as hortaliças, também variando ao longo do ciclo de vida da planta. Por não entenderem essa complexidade adequadamente, os produtores orgânicos produziam hortaliças pequenas e feias. A justificativa é esses aspectos seriam "um imperativo da produção orgânica", pois não utilizavam adubos químicos nem agrotóxicos.

Tive a sorte de me tornar sócio na produção, no meu sítio, de um dos melhores agrônomos orgânicos brasileiros, Luiz Geraldo de Carvalho. Juntos, conseguimos trilhar um caminho de experimentação que nos levou a produzir organicamente com qualidade e produtividade. Enquanto a maioria dos agrônomos e produtores ficava ancorada na produção de hortaliças orgânicas utilizando como componente de nutrição esterco ou cama de galinha, composto orgânico de esterco e adubação verde, nós adotamos radicalmente a "teoria da Trofobiose", criada por Francis Chaboussou.

Como resultado de nossa experimentação, conseguimos desenvolver vários tipos de biofertilizantes orgânicos, com diferentes formulações e concentrações de nutrientes produzidos a partir de uma gama diversificada de matérias primas. Definimos uma formulação especifica de acordo com a demanda nutricional para cada hortaliça e para cada fase do seu desenvolvimento. Essa técnica, somada a uma relativa especialização na produção de hortaliças, produziu um primeiro ciclo de aumento de qualidade e produtividade. Em 2002, já preconizávamos que um agricultor deveria manejar, no máximo, seis espécies de hortaliças ao mesmo tempo em sua propriedade, porque era necessário equilibrar as necessidades ecológicas de diversificação com a capacidade administrativa e a uniformização da produção para atender às possibilidades do mercado.

$O$ aumento da produtividade que alcançamos foi de tal ordem que a feira da AAO já não era mais capaz de absorver a produção. Por isso, em janeiro de 1995, fundamos a "Associação de Produtores Horta \& Arte" e passamos a vender hortaliças orgânicas em espaços de supermercados paulistanos. Iniciamos com uma Kombi, entregando em dias alternados, mas, em um ano, já estávamos entregando diariamente dois caminhões de hortaliças orgânicas. Nos anos seguintes, mais 135 famílias de produtores entraram para a associação e chegamos a entregar, diariamente, vinte e dois caminhões de hortaliças orgânicas nas cidades da Grande São Paulo, Baixada Santista, Rio de Janeiro, Porto Alegre, Belo Horizonte e Brasília. Além desses locais, conseguimos exportar nossas hortali- 
ças para Inglaterra, Estados Unidos e Holanda. O trabalho da "Horta \& Arte" tornou-se referência em todo o país, pois foi um dos pilares para dar visibilidade aos produtos orgânicos e ganhar o grande mercado de varejo, no qual a maior parte da população brasileira compra seus alimentos.

Esse sucesso despertou o interesse de muitos produtores convencionais, muitos deles demonstrando interesse em produzir organicamente porque estávamos conquistando o seu mercado de hortaliças. Éramos receptivos a esses novos agricultores, mas o maior obstáculo era a má-fé dos distribuidores que atuavam no grande varejo. Sem nenhuma ética, começaram a embalar e vender produtos convencionais como orgânicos. Por esse motivo, no fim dos anos 1990, começamos a discutir com a AAO a criação de um selo de certificação orgânica para o mercado brasileiro, nos moldes da certificação orgânica da International Federation of Organic Movements (IFOAM). O processo de certificação e o uso do selo nas embalagens dos produtos orgânicos aconteceram concomitantemente com o desenvolvimento do selo por outras organizações, tais como o Instituto Biodinâmico (IBD) e a Fundação Mokiti Okada, que propõe a "agricultura natural".

Os selos não eram de uso obrigatório sob o ponto de vista legal. No entanto, ganharam uma ampla credibilidade, e, gradualmente, nenhum varejista de supermercado aceitava um distribuidor de produtos orgânicos sem selo. Foi nesse contexto que surgiu a necessidade de criação de um marco legal brasileiro para os processos de certificação orgânica e uso de selo.

\section{SURGE A AGROECOLOGIA NO CENÁRIO}

Durante o processo de criação desse marco legal, convivi com um grupo identificado com os chamados "princípios da agroecologia". Até me tornar produtor orgânico, nunca tinha ouvido o termo agroecologia. Conhecia apenas as diferentes linhas do campo da agricultura alternativa - orgânica, biológica, biodinâmica e natural. O termo agroecologia, contudo, era, para mim, totalmente desconhecido.

Durante a construção do marco legal da agricultura orgânica no Brasil, fomos surpreendidos pela proposta de um modelo de certificação denominado "certificação participativa". Esse modelo se contrapunha ao modelo de "certificação de terceira parte", que já era o modelo consagrado e utilizado pelos agricultores orgânicos inseridos no mercado de varejo. Notei que muitos dos argumentos daqueles defensores da certificação participativa eram claramente "antimercado". Ainda em 2002, participei do "I Encontro Nacional de Agroecologia" (I ENA) e percebi que aqueles citados "princípios da agroecologia" lembravam as discussões que foram mantidas no II Encontro Brasileiro de Agricultura Alternativa (1987).

No II EBAA, de um lado, estavam os ecologistas "puros", que defendiam o desenvolvimento de uma agricultura ecológica e sustentável do ponto de vista ambiental. Do outro lado, estavam os ecologistas "revolucionários", os quais preconizavam uma mudança no modelo de produção econômico como um todo, afetando toda estrutura econômica e não somente nos padrões técnicos de produção agrícola. Em síntese: eram, primeiramente, visões anticapitalistas. Ou seja, os revolucionários agregavam os movimentos sociais de esquerda, a esquerda revolucionária e os socialistas de todas as estirpes. Os 
ecologistas puros agregavam técnicos preocupados com a sustentabilidade da produção agrícola do ponto de vista ambiental e da qualidade dos alimentos e não comungavam com nenhuma cartilha revolucionária visando a "transformação da sociedade".

Obviamente que, pela minha trajetória de vida, eu me identificava com os ecologistas revolucionários. Entretanto, como o mundo gira e o muro de Berlim foi derrubado em 1989, dois anos após o II EBAA, o discurso da esquerda teve que se adaptar aos novos tempos e encontrar novas bandeiras em função do fiasco econômico e social das experiências dos países socialistas. Eu também mudei meu posicionamento ideológico ao tomar conhecimento da revolta das populações desses países com a sua pobreza material e a baixa qualidade de vida e, principalmente, com o sofrimento em função da bárbara repressão perpetrada para manter um modelo econômico e político socialmente indesejado e disfuncional.

Quando li o artigo de Zander Navarro (2013), de pronto identifiquei o cerne da divisão que ocorreu no II EBAA e voltou a se repetir durante o processo de construção do marco legal da agricultura orgânica no Brasil - e permanece até hoje. A mesma polarização entre ecologistas puros e revolucionários socialistas, embora travestida em nova roupagem. Em uma expressão maniqueísta, os ecologistas puros transformaram-se nos "produtores malvados do agronegócio orgânico", e os socialistas revolucionários tornaram-se os "agroecologistas defensores do bem". Como o artigo aqui comentado realça, obviamente muitos dos que se dizem agroecologistas são novos convertidos que empunham, junto com a questão da sustentabilidade ecológica, a bandeira das transformações sociais (e econômicas) sem muita clareza sobre quais "novos" modelos (econômicos) estão de fato sendo defendidos. O maior problema, todavia, que o autor identifica é que as reais intenções revolucionárias do ponto de vista social e econômico da agroecologia estão difusas em um discurso que não é claro para a maior parte do público cooptado pelos formuladores da agroecologia. Não se explicita que essa liderança é, antes de tudo, anticapitalista e antimercado.

Desse modo, o problema não é manter tais posturas políticas. O problema é não ser explicitamente claro com relação a essa opção. A maioria dos artigos sobre agroecologia disponíveis não explicita com clareza que modelo social e econômico "alternativo e sustentável" está sendo proposto. O discurso é quase sempre o mesmo, ou seja, nada do que está disponível atualmente serve para o novo modelo que está sendo construído. O que serviria, então, em substituição?

\section{QUAL SERIA O CAMINHO?}

Nesta seção busca-se discutir alguns parâmetros gerais de duas possíveis alternativas de modelo para a agricultura agroecológica. Se a análise anterior sugere que entre os "princípios da agroecologia" está o pilar dogmático da opção antimercado, não tenho muito mais o que criticar construtivamente. É uma opção da qual discordo radicalmente e não me encanta contribuir com ela. Se a minha análise anterior está equivocada e a opção antimercado não faz parte dos nomeados princípios da agroecologia, em busca da chamada sustentabilidade social e econômica, pergunto: qual seria a diferença fundamental com relação aos outros modelos de agricultura alternativa e ecológica? 
A publicação "Agroecologia: alguns conceitos e princípios", de Francisco Roberto Caporal e José Antônio Costabeber (2004), sistematiza algumas ideias a respeito. Entre os "princípios da agroecologia", estaria o de "aprender com os agricultores". Dessa forma, podemos nomear a diversidade de agricultores que contribuiriam, potencialmente, na construção de modelos agroecológicos. Gostaria de destacar dois grandes grupos de agricultores: um grupo focado principalmente no autoconsumo e, consequentemente, com pouca ou nenhuma troca comercial; o outro grupo estaria focado no mercado. Não desconsiderando a importância social do primeiro grupo de agricultores, gostaria de salientar a importância do segundo grupo, uma vez que $84 \%$ da população brasileira (168 milhões de pessoas) vivem em agrupamentos urbanos e demandam a existência de agricultores focados em atender às suas necessidades alimentares.

Discute-se, entre os defensores da agroecologia, a necessidade de resolver os problemas socioambientais que a agricultura convencional teria gerado e que as chamadas agriculturas ecológica ou orgânica não conseguiram superar. Segundo a agroecologia, a solução para resolver esses problemas socioambientais é o desenvolvimento rural, por meio da expansão de agroecossistemas sustentáveis. Esses sistemas incluiriam as relações socioeconômicas entre todos os agentes de mercado, explicitando que fazem parte dessas relações os agricultores, os consumidores de produtos agrícolas (não só de alimentos) e todos os demais componentes das cadeias de transformação, distribuição e comercialização que atuam entre as pontas?

Para ser mais preciso, os 168 milhões brasileiros necessitam não só de alimentos básicos in natura, mas precisam de inúmeros itens indispensáveis provenientes da agricultura, que passam por cadeias longas de industrialização e distribuição, tais como celulose (papel higiênico, absorventes, livros), incontáveis alimentos industrializados (massas, pães, laticínios, bebidas, entre infinitos outros produtos), madeiras (construção civil, movelaria, logística, e muitos outros), fibras (algodão, coco, sisal para indústria de estofamentos, automotiva, etc.), espécies vegetais e animais para indústria farmacêutica e química, couro e muitos outros exemplos que poderiam ser citados. Se os agroecologistas querem verdadeiramente desenvolver agroecossistemas ecológicos, devem trazer para o centro da discussão todas as necessidades da população que vive nas cidades, os agricultores focados em atender a essas necessidades e todas as cadeias de industrialização e distribuição. Como criar agroecossistemas sustentáveis, considerando todos os agentes elencados acima e a necessidade de atender aos componentes básicos de mercado, como os padrões de concorrência, escala, produtividade, padronização, logística, custo, comunicação, para citar apenas alguns dos focos principais? Sem uma revolução na estrutura econômica, nenhum agricultor que queira atender às necessidades da população pode fugir da lógica de mercado. Em última instância, é o consumidor final quem vai determinar, pelas suas escolhas, os "agroecossistemas vencedores", ou seja, aqueles que vão permanecer existindo nas atividades agropecuárias.

\section{CURTAS HISTÓRIAS, A TÍTULO DE CONCLUSÃO}

Por fim, apresentam-se algumas pequenas histórias ou situações vivenciadas na "Horta \& Arte" e que demonstram o poder determinante do mercado. 
Primeira, quando resolvemos não utilizar mais as bandejas de EPS (conhecidos pela marca líder, isopor) que usávamos para embalar legumes in natura, passamos a expor, em várias lojas de grandes supermercados, como Carrefour, Wal-Mart e Extra, os produtos em bancas com produtos orgânicos para serem vendidos a granel. Para nossa surpresa, o público consumidor de alimentos orgânicos, supostamente mais esclarecido do ponto de vista ecológico, mesmo em face de uma comunicação que explicitava o problema ambiental do uso continuado das embalagens de EPS, simplesmente ignorou a opção de compra a granel e continuou a comprar os alimentos orgânicos embalados. Registre-se que os alimentos embalados eram mais caros.

A segunda é sobre o canal de vendas utilizado pela empresa. Quando iniciamos o nosso trabalho nos supermercados, fomos o alvo de severas críticas por grande parte do movimento de agricultura alternativa, pois o supermercado era entendido como apenas um agente de intermediação na relação entre o agricultor e o consumidor final. O ideal defendido pelo "movimento" é que, quanto menor a cadeia de distribuição, melhor seria para o agricultor. Por isso, a opção preferencial era pelas feiras de produtor. No entanto, na Grande São Paulo, no início dos anos 1990, 70\% dos produtos FLV (frutas, legumes e verduras) eram vendidos em feiras livres e o restante nos supermercados. No final dos anos 1990, contudo, essa distribuição inverteu-se totalmente, e dois terços dos produtos FLV passaram a ser vendidos em supermercados e o outro terço nas feiras livres. Como a "Horta \& Arte" distribuía para o canal de vendas escolhido pelos consumidores, mas esses migraram das feiras livres para os supermercados, os agricultores ligados a H\&A puderam aproveitar o aumento dessa demanda e crescer exponencialmente, incrementando renda e qualidade de vida.

A terceira relaciona-se com o modelo tecnológico de produção orgânica adotado na empresa. Desenvolvemos um modelo fortemente criticado pela agroecologia, pois é baseado em insumos orgânicos (biofertilizantes) e outros insumos não necessariamente orgânicos, mas permitidos (como as sementes convencionais) e com cada agricultor associado produzindo um número reduzido de hortaliças. $O$ ideal defendido pela agroecologia é input zero de insumos externos na propriedade, diversificação de espécies, integração das produções vegetal e animal, uso de espécies adaptadas, produção das próprias sementes, entre outros "princípios". Assim, a crítica do movimento da agroecologia era a de que o modelo da H\&A era menos "ecológico" e menos "sustentável" por ser menos complexo. Além disso, o movimento também alegava que modelos ecológicos e sustentáveis são necessariamente complexos, por isso nosso modelo era menos ecológico e menos sustentável.

Foi justamente em função desse paradigma do que é mais ecológico e sustentável que a H\&A quebrou. Isso porque só é sustentável o que se sustenta (existe) ao longo do tempo. Para isso, é importante constatar que hoje os produtos orgânicos (ecológicos ou naturais) existentes nos supermercados, que atendem às necessidades dos consumidores e impactam positivamente uma grande área de produção agrícola, são baseados nesse modelo de "agricultura orgânica simples", ou seja, sem seguir todos aqueles preceitos sugeridos pelo movimento da agroecologia.

Para que um agricultor (pequeno ou grande, familiar ou empresarial) integrado ao mercado adote um sistema de produção agrícola, ele precisa ter lucro (ainda que a 
nossa América Católica, que não é socialista, e nossos socialistas, que não são católicos, ainda tenham medo dessa palavra). Obter lucro em um empreendimento não significa necessariamente degradação ambiental, exploração, expropriação ou outros efeitos danosos. Para que um empreendimento confira lucro, ele precisa ser eficiente. Para isso, é necessária uma gestão eficiente. Quanto mais simples for a gestão, maior será a possibilidade de um empreendimento ser eficiente e lucrativo. Minha experiência na $H \& A$ ensinou-me que é necessário ter simplicidade na gestão.

Um produtor de hortaliças orgânicas perde foco e eficiência administrativa e econômica quando necessariamente precisa: (a) investir seu tempo no melhoramento vegetal das variedades que usará na sua produção; (b) produzir as sementes que serão utilizadas na produção de hortaliças; (c) gerenciar a produção animal para utilizar o esterco na produção hortícola; (d) produzir as mudas que serão transplantadas para a sua produção; (e) gerenciar várias espécies de hortaliças ao mesmo tempo.

Não foi somente por causa da pressão do complexo industrial de insumos e dos aparatos de extensão rural que a agricultura química deu certo. A sua gestão é muito mais simples. É fácil de ser entendida e apropriada pelos agricultores, e esse foi, na realidade, um dos pilares do grande sucesso da revolução verde: simplicidade da gestão dos fatores de produção (é preciso existir a "receita de bolo").

Na minha avaliação, esse foco da agroecologia em sistemas totalmente adaptados às condições de solos e climas, que prescindam do uso de insumos externos à propriedade, com estímulo a uma diversificada produção vegetal e animal em uma mesma propriedade, torna os agrossistemas extremamente complexos e dificílimos de gerenciar. Isso ocorre principalmente quando comparados aos sistemas simples da agricultura convencional ou da chamada (e criticada) agricultura orgânica de insumos. Esses sistemas complexos dificilmente atrairão os agricultores integrados ao mercado, os quais atendem às necessidades da maioria dos brasileiros. Por isso, entendo que a visão do movimento de agroecologia está muito longe da realidade desse agricultor.

É necessário buscar um equilíbrio, um caminho que atenda às necessidades dos consumidores urbanos (mercado) e à necessidade de preservação ambiental. Caso contrário, a proposta dos agroecologistas fará com que os agrossistemas propostos por eles fiquem fadados a obter a adesão somente do grupo de agricultores ligados à produção para autoconsumo. Em síntese, é preciso aceitar que in medio virtus est (a virtude está no meio).

\section{REFERÊNCIAS}

CAPORAL, Francisco Roberto; COSTABEBER, José Antônio. Agroecologia: alguns conceitos e princípios. Brasília: 2004. Disponível em: <http://agroeco.org/socla/wp-content/ uploads/2013/11/Agroecologia-Conceitos-e-princpios1.pdf>. Acesso em: 5 mar. 2014.

NAVARRO, Z. Agroecologia: as coisas em seu lugar (a Agronomia brasileira visita a terra dos duendes) Colóquio - Revista do Desenvolvimento Regional - Faccat, Taquara, v. 10, n. 1, jan./jun. 2013. 